\title{
Antimonium crudum in pediatric skin conditions, a classical homeopathic case series
}

\author{
Seema Mahesh ${ }^{1}$, Tamara Kozymenko ${ }^{2}$, Nataliia Kolomiiets ${ }^{3}$, and George Vithoulkas ${ }^{4}$ \\ ${ }^{1}$ Taylor's University - Lakeside Campus \\ ${ }^{2}$ Kyiv Medical University of UAFM \\ ${ }^{3}$ Center of classical homeopathy of Nataliia Kolomiiets \\ ${ }^{4}$ Postgraduate Doctors' Training Institute
}

November 4, 2020

\begin{abstract}
We present three cases of impetigo and one case of bullous pemphigoid neonatorum that benefited from the homeopathic remedy Antimonium crudum, which has a wide spectrum of dermatological applications when prescribed according to symptom similarity. Further larger clinical studies are necessary to establish its role in pediatric dermatology.
\end{abstract}

Antimonium crudum in pediatric skin conditions, a classical homeopathic case series

Seema Mahesh $^{1 *}$, Tamara Kozymenko ${ }^{2}$, Nataliia Kolomiiets ${ }^{3}$, George Vithoulkas ${ }^{4,5}$

1School of medicine, Faculty of Health and Medical Sciences, Taylor's University, Malaysia; ORCID: 00000002-4765-5595

2 Private Higher Educational Establishment Kyiv Medical University, Kyiv, Ukraine

3 Center of classical homeopathy of Nataliia Kolomiiets, Kyiv, Ukraine

4Postgraduate Doctors' Training Institute, Health Care Ministry of the Chuvash Republic, Cheboksary, Russian Federation;

ORCID: 0000-0002-9118-8306

5International Academy of Classical Homeopathy, Alonissos, Greece

Short Title: Pediatric skin conditions and homeopathy

\section{Corresponding Author:}

Seema Mahesh,

School of medicine, Faculty of Health and Medical Sciences,

Taylor's University, Malaysia

No 1 Jalan Taylors, Subang Jaya, 47500

Selangor, Malaysia

Email: bhatseema@hotmail.com;

Tel: +600123809077 


\section{Key Clinical Message}

Homeopathic Antimonium crudum may be useful in many pediatric skin conditions if prescribed on symptom similarity. It may especially be helpful in reducing the use of antibiotics and steroids in this age group if proven to be effective through larger scientific studies.

\section{Abstract}

We present three cases of impetigo and one case of bullous pemphigoid neonatorum that benefited from the homeopathic remedy Antimonium crudum, which has a wide spectrum of dermatological applications when prescribed according to symptom similarity. Further larger clinical studies are necessary to establish its role in pediatric dermatology.

Keywords: pediatric dermatology, impetigo, bullous pemphigus, homeopathy

\section{Background}

Impetigo (ICD 10 L01.00) ${ }^{1}$ is one of the most common pediatric skin complaints, caused by gram positive bacteria and highly contagious. It may occur as a primary infection of the epidermis or secondary to any trauma or breach in the skin. While the exact prevalence is unclear, it is estimated to account for $10 \%$ of pediatric skin complaints. Males and females are equally affected, and it is more common in the 2- to 5-year-old age group. It shows a seasonal tendency and is more prevalent in the hot/humid seasons, i.e., summer and fall ${ }^{2,3}$.

The causative organism is mostly Group A Streptococcus (GAS) in the non-bullous type and Streptococcus aureus in the bullous type. Breaches in skin integrity expose fibronectin receptors, promoting bacterial colonization. Self-inoculation helps the lesions spread further ${ }^{2,3}$. Clinically, these two types show distinct patterns. Non-bullous impetigo often appears as vesicles that coalesce and rupture, and the purulent exudate forms the characteristic honey-colored crust. The ruptured area exhibits an erythematous base. Rapid spread and satellite lesions can occur, with mild regional lymphadenopathy. Systemic symptoms such as fever are typically absent. The bullous type almost exclusively affects infants. It usually presents as vesicles that form flaccid bullae containing yellow or dark colored fluid. This may rupture, exposing an erythematous base and rim. Honey-colored crusts are not formed in bullous impetigo. Usually, no lymphadenopathy occurs, and fever is a common presentation ${ }^{2,3}$.

Malnutrition, diabetes, and immune suppression predispose individuals to the development of impetigo. It is also triggered by other viral infections, such as herpes and varicella, and other causes of skin breach, such as burns, trauma and insect bites ${ }^{3}$.

Management typically involves topical and oral antibiotics. Approximately $20 \%$ of impetigo cases are capable of self-resolution, and antibiotics have been shown to shorten the disease duration and avert complications that may affect the kidneys, impact the joints or result in acute rheumatic fever. Without treatment, impetigo will resolve in two to three weeks; with treatment, it will resolve in 10 days $^{3}$. Some antibiotic applications have shown that clinical clearance can occur in 5 days and microbiological clearance will occur in 3 to 4 days ${ }^{4,5}$.

The second condition, which we present here, unlike impetigo, is quite rare. While the actual incidence has not been investigated, bullous pemphigoid is a rare condition in the pediatric age group (ICD 10 L12.0) $)^{1}$ It is an immune-mediated autoimmune disease, exhibiting circulating autoantibodies to antigens BPA1/BP230 and BPA2/BP180 (collagen VVII-NC16A). The initiation of the disease occurs with the IgG recognition of BP180 antigen. Acral involvement of the bullae is a common presentation in the infantile type and may be diagnosed by the presence of $\mathrm{C} 3$ and $\mathrm{IgG}$ deposition in the skin biopsy. It usually has excellent prognosis as it responds very well to corticosteroids. The response time varies from a few weeks to a few months, but complete resolution within one year is expected. In 2014, a treatment algorithm was proposed that delineated the approach to mild and severe forms of the disease. The first line of treatment is topical steroids and in case of severe disease, involving more than $10 \%$ of the body surface area. A systemic steroid must be introduced, 
which is withdrawn slowly upon remission. In cases of refractory disease, G6PD deficiency must be ruled out ${ }^{6,7}$.

We present here four patients with pediatric skin conditions that were cured by the homeopathic medicine Antimonium crudum.

\section{Case Series:}

We present 4 cases of pediatric dermatological conditions that benefited from homeopathic Antimonium crudum. Three of these children had impetigo, and one had bullous pemphigoid neonatorum. These patients were treated by homeopathic physicians in Ukraine.

Case 1 (Fig. 1):

A 7-year-old Ukrainian boy presented on 7/6/2015 with rapidly spreading lesions on the face, nose and arms. There was a crack in the left nostril. The lesions seemed to be impetigo. This occurred after swimming and diving in a cold pool. In one day, the left nostril was completely blocked with honey-colored crusts, which became hard-like stones, with pus discharging from the skin below both nostrils. More small foci appeared on the face and body

Diagnosis: The diagnosis made by clinical features and the parents called the homeopath.

Prescription: The first prescription was Mercurius solubilis 200C, which had no effect. Then, one dose of Antimonium crudum $30 \mathrm{C}$ was given.

Follow-up: The next morning, all small crusts disappeared from the face and nose, greenish nasal discharge appeared, and large crusts started bleeding. Antimonium crudum $200 \mathrm{C}$ was given, and in one day, all lesions healed.

Case 2 (Fig. 2):

A 5-month-old Ukrainian male infant was brought to the homeopath with skin eruptions diagnosed by the dermatologist as impetigo (streptodermia). The eruptions appeared at the age of 3 months in May 2014 during a cold after hypothermia, first on the chin and cheeks, then on the neck and back of head, then on hands, nates, genitalia and heels. The eruptions were periodical, with eruptions appearing every 2 weeks. There was a cyclical character of the lesions as well, appearing successively as vesicles, ulcers, crusts, and desquamations (Fig 2). The boy was calm and smiling during the day, only crying when being washed with cold water. However, during the night, he was very restless. The period of the aggravation of eruptions was accompanied by constipation, vomiting after nursing and thick, abundant saliva. The eruptions were aggravated after bathing. The tongue was covered with thick white mucus. No conventional treatment was given.

Diagnosis: Clinical diagnosis was made by the homeopathic physician

Prescription: On 20/7/2014, Antimonium crudum 12C once a day was prescribed.

Follow-up: After 3 weeks, the mother noticed that the usual 2-week cycle of the eruptions did not appear. The remedy was stopped.

After 2 months, the skin became clear completely. The child had no problem with the skin during the 6 years of follow-up.

Case 3 (Fig. 3):

A 6-year-old Ukrainian boy presented with skin eruptions. The boy often visited a swimming pool with heated water, but on one occasion, the water was cold. After a few days of bathing in cold water, a wet spot appeared inside the right hand with small pimples. Many vesicles appeared on the face, body and arms, which opened with sticky discharges forming thick yellow crusts (Fig 3). 
Diagnosis: was made based on clinical features by the homeopathic physician

Prescription: Graphites 30C was prescribed on 10/9/2014, and Graphites 200C was prescribed on 11/9/2014. The skin condition worsened; some large blisters appeared on the forehead, finger, and arms. Severe eruptions appeared around the eyes and under the right arm. He could not open the eyes or raise the right arm. The eruptions were itching with burning. The child peeled off the crusts during night sleep and was very irritated. The area under the right arm looked as if scalded and was very painful. New vesicles appeared on the left arm.

On 16/9/2014, Antimonium crudum $10 \mathrm{M}$ was given

Follow-up: On 17/9/2014, the spreading of eruptions stopped, itching subsided, and moist eruptions dried and developed crusts, which detached without discharging. The face was completely clear.

On 20/9/2014, only light crusting on left upper limb and armpit remained; other areas were clear.

On 27/9/2014, all skin eruptions disappeared, and the skin became clear.

Case 4 (Fig. 4)

A 10-day-old female Ukrainian infant living in the USA with bullous pemphigus neonatorum was seen by a homeopath. On the 7th day after birth, yellow blisters appeared in the left armpit, which then opened and became wet on the surface with a yellow sticky discharge (Fig 4). In the hospital, the patient was diagnosed with "bullous pemphigoid neonatorum", and immediate introduction of intravenous antibiotics for sepsis prevention was recommended. Meanwhile, patients consulted the Ukrainian homeopath via video consultation. The infant had thick white mucus on the tongue that was similar to candidiasis. The general condition, sleep and appetite were normal, and the baby was not vaccinated.

Prescription: One dose of Antimonium crudum 30C was given on 30/3/2018.

Follow up: Immediate changes were appreciated, averting the need for antibiotics.

On 6/4/2018, purulent discharges were completely reduced, and no further spread of eruptions was observed.

On 13/4/2018, all skin eruptions disappeared, but some pigmentation remained.

On $8 / 8 / 2020$, the child was clear of the complaint with no relapses so far.

\section{Discussion}

Classical homeopathy approaches any condition in a holistic, individualized manner. This means that it takes into consideration the hereditary predisposition, circumstantial stress, diseases suffered in the past, immune response characteristics, drugs given, responses to these drugs and the current diagnosis with detailed symptomatology to choose a remedy ${ }^{8,9}$. The homeopathic pharmacopoeia includes many drugs that have an action predominantly on the skin ${ }^{10}$, and many disparate conditions have shown excellent response clinically to them ${ }^{11-14}$. Nwabudike in 2016 published a homeopathic case report of impetigo in an elderly man ${ }^{15}$ who benefited from a different homeopathic medicine, Hepar sulphuricum.

Antimonium crudum, the black sulphide or native sulphide of antimony, is another such medicine that has an effect on skin conditions ${ }^{16,17}$, prepared homeopathically according to Class VII of Indian pharmacopeia 18. The semiotic similarity between the symptoms produced during proving of Antimonium crudum and those produced in the patient gives us the indication about which dermatological conditions the medicine will be serviceable homeopathically in ${ }^{16}$. The action of this homeopathic preparation has been proven to be beneficial in murine leishmaniasis through a distinct promotion of B cell activity ${ }^{19,20}$. The medicine exhibited immunomodulating activity where it promoted Th1 predominance and helped control the infection process $^{21}$.

In the cases we have presented, the first three were infections, and the last one was an autoimmune condition. The indications for homeopathic medicine, however, do not stop at diagnosis. The same remedy may be 
indicated in infections or autoimmune conditions because of the other associated symptoms, especially those that do not seem to be a direct consequence of the pathology. For example, patients requiring Antimonium crudum usually have a very thick milky white coating on their tongue. They also have an unexplainable craving for cucumbers ${ }^{16,22}$. The common line running in the above cases was aggravation at night and aggravation from cold bathing. Such peculiarities may seem insignificant, but to homeopaths, they are of paramount importance. The idea is that in a diseased state, it is not just the local organ or system that is affected but rather a general affection occurs, altering many faculties of the being. Considering this entire profile alone indicates to the right medicine. This idea is no longer far-fetched, as studies show the systemic nature of inflammation, immune response and sickness behavior ${ }^{23,24}$. While these are being studied in a generalized manner by conventional medicine to understand the common changes in the whole spectrum of disease, homeopathy considers these changes at the individual level and has treated so since the last two centuries. In these cases, such an approach was proven to be beneficial.

\section{Conclusions:}

The homeopathic medicine Antimonium crudum was beneficial in the four cases of pediatric skin conditions presented here. The relevance of this drug in homeopathic potencies to dermatological conditions needs to be investigated further with scientific studies.

\section{Statements}

Statement of Ethics Ethical approval was not sought as the report is from treatment results and not a trial. The patients' parents were explained about the publication and they have provided written consent for publication.

Consent for publication: Written consent was obtained from parents for publication of their wards' case details and photographs.

Conflict of Interest Statement

The authors have no conflicts of interest to declare.

Funding Sources

No funding was obtained for this work

Author Contributions

TK and NK were the primary physicians who treated the patients, obtained the data and analyzed them for the study. SM wrote the manuscript and obtained the references. GV was the guide, final approver and guarantor of the work. All authors have read and approved the final version of the manuscript

\section{References}

1. World Health Organization. ICD-10 : international statistical classification of diseases and related health problems : tenth revision. In. 2nd ed ed. Geneva: World Health Organization; 2004.

2. Newberger R, Gupta V. Streptococcus Group A. In: StatPearls.Treasure Island (FL): StatPearls Publishing

Copyright (C) 2020, StatPearls Publishing LLC.; 2020.

3. Nardi NM, Schaefer TJ. Impetigo. In: StatPearls. Treasure Island (FL): StatPearls Publishing

Copyright (C) 2020, StatPearls Publishing LLC.; 2020.

4. Rosen T, Albareda N, Rosenberg N, et al. Efficacy and Safety of Ozenoxacin Cream for Treatment of Adult and Pediatric Patients With Impetigo: A Randomized Clinical Trial. JAMA Dermatol.2018;154(7):806-813.

5. Torrelo A, Grimalt R, Masramon X, Albareda López N, Zsolt I. Ozenoxacin, a New Effective and Safe Topical Treatment for Impetigo in Children and Adolescents. Dermatology. 2020;236(3):199-207. 
6. Ferreira BR, Vaz AS, Ramos L, Reis JP, Gonçalo M. Bullous pemphigoid of infancy - report and review of infantile and pediatric bullous pemphigoid. Dermatol Online J. 2017;23(2).

7. Schwieger-Briel A, Moellmann C, Mattulat B, et al. Bullous pemphigoid in infants: characteristics, diagnosis and treatment. Orphanet $J$ Rare Dis. 2014;9:185-185.

8. Hahnemann S. Organon of medicine. B. Jain publishers; 2002.

9. Vithoulkas G. The science of homeopathy. B. Jain Publishers; 2002.

10. Vithoulkas Compass v5.1. Vithoulkas Compass; 2020. https://vc.vithoulkascompass.com/\#url=mycompass/index.

11. Mahesh S, Vithoulkas G, Mallappa M. Gangrene: Five case studies of gangrene, preventing amputation through Homoeopathic therapy. Indian Journal of Research in Homoeopathy. 2015;9(2).

12. Mahesh S, Mallappa M, Tsintzas D, Vithoulkas G. Homeopathic Treatment of Vitiligo: A Report of Fourteen Cases. Am J Case Rep.2017;18:1276-1283.

13. Mahesh S, Shah V, Mallappa M, Vithoulkas G. Psoriasis cases of same diagnosis but different phenotypesManagement through individualized homeopathic therapy. Clin Case Rep. 2019;7(8):1499-1507.

14. Nwabudike LC. Palmar and plantar psoriasis and homeopathy - Case reports. Our Dermatology Online. 2017;8(1):66-69.

\section{NWABUDIKE LC. IMPETIGO AND HOMEOPATHY-A CASE STUDY.}

16. Kent JT. Lectures on Materia Medica. New Delhi, India: B Jain Publishers Pvt Ltd; 1995.

17. Clarke JH. A Dictionary of Practical Materia Medica. Vol 1. New Delhi: B Jain Publshers Pvt Ltd; 1999.

18. India Homoeopathic Pharmacopoeia Committee, India Ministry of Health, Family Welfare. Homoeopathic Pharmacopoeia of India (H.P.I.). Controller of Publications; 1974.

19. Rodrigues de Santana F, de Paula Coelho C, Cardoso TN, et al. Modulation of inflammation response to murine cutaneous Leishmaniasis by homeopathic medicines: Antimonium crudum 30cH. Homeopathy.2014;103(4):264-274.

20. de Santana FR, Dalboni LC, Nascimento KF, et al. High dilutions of antimony modulate cytokines production and macrophage - Leishmania (L.) amazonensis interaction in vitro. Cytokine. 2017;92:33-47.

21. Cajueiro APB, Goma EP, Dos Santos HAM, et al. Homeopathic medicines cause Th1 predominance and induce spleen and megakaryocytes changes in BALB/c mice infected with Leishmania infantum. Cytokine.2017;95:97-101.

22. Vithoulkas G. Materia Medica Viva. International Academy of Classical Homeopathy; 1997.

23. Dantzer R, O'Connor JC, Freund GG, Johnson RW, Kelley KW. From inflammation to sickness and depression: when the immune system subjugates the brain. Nat Rev Neurosci. 2008;9(1):46-56.

24. Mezzano S, Olavarría F, Ardiles L, López MI. Incidence of circulating immune complexes in patients with acute poststreptococcal glomerulonephritis and in patients with streptococcal impetigo.Clin Nephrol. 1986;26(2):61-65.

\section{Figure Legends}

Fig. 1. Case 1 presentation and treatment result

Fig. 2. Case 2 presentation and treatment result

Fig. 3. Case 3 presentation and treatment result

Fig. 4. Case 4 presentation and treatment result 
Fig 1: Case 1 Presentation and treatment result
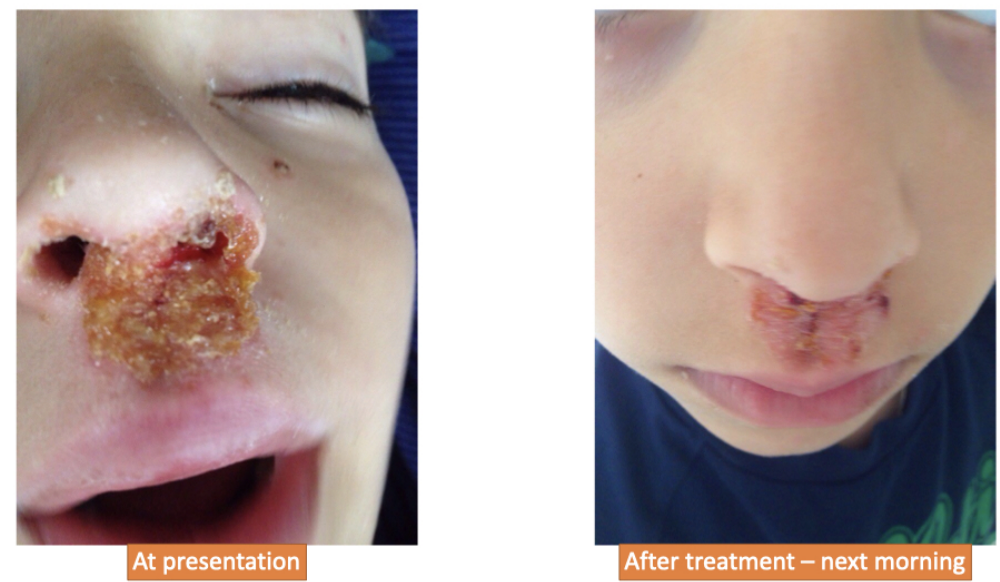

After treatment - next morning

Fig 2: Case 2 Presentation and treatment result

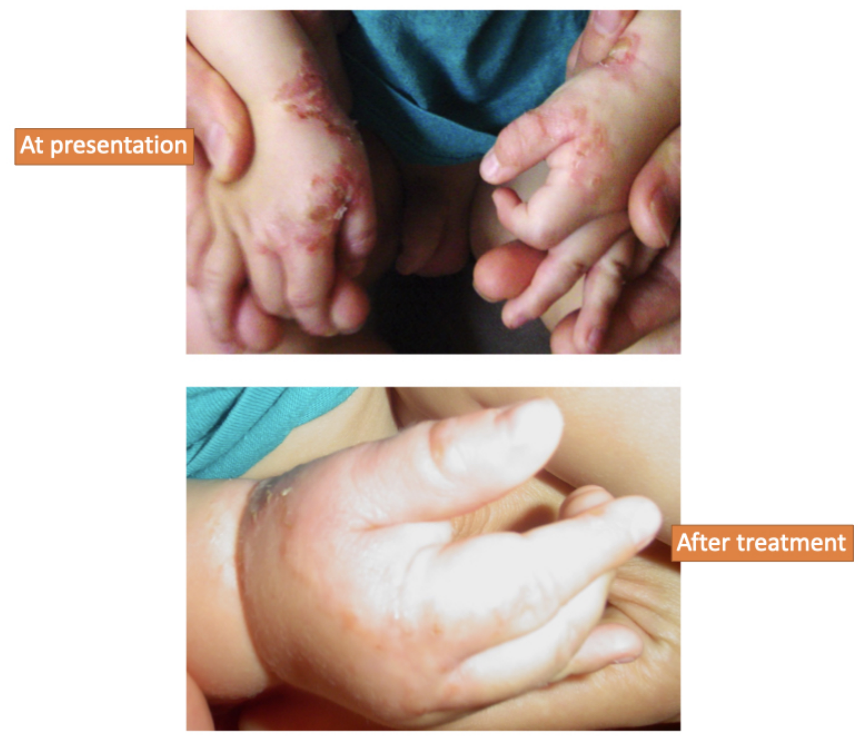




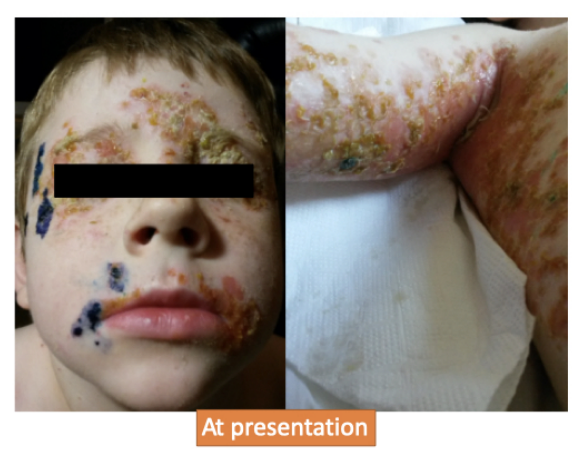

Fig 3: Case 3 Presentation and treatment result
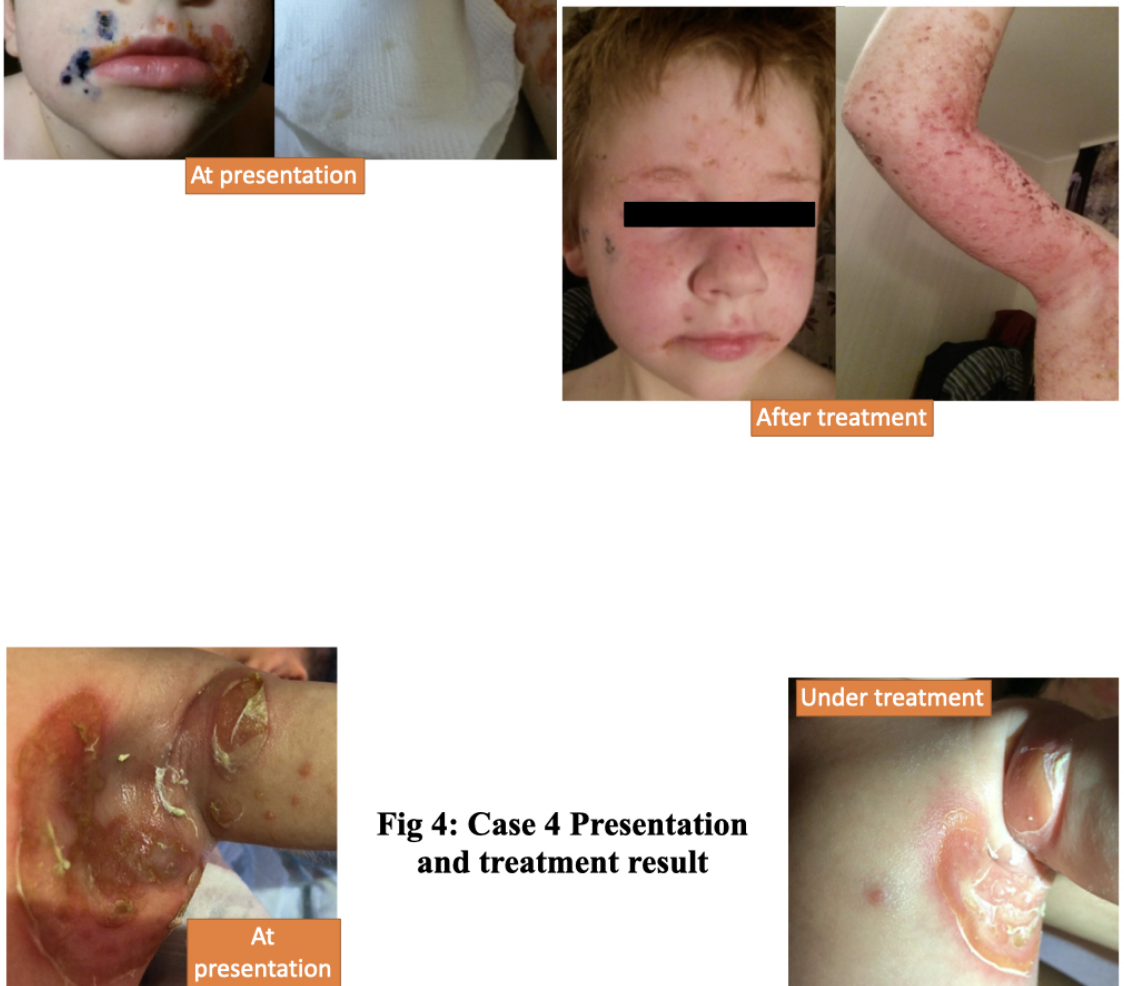

Fig 4: Case 4 Presentation and treatment result
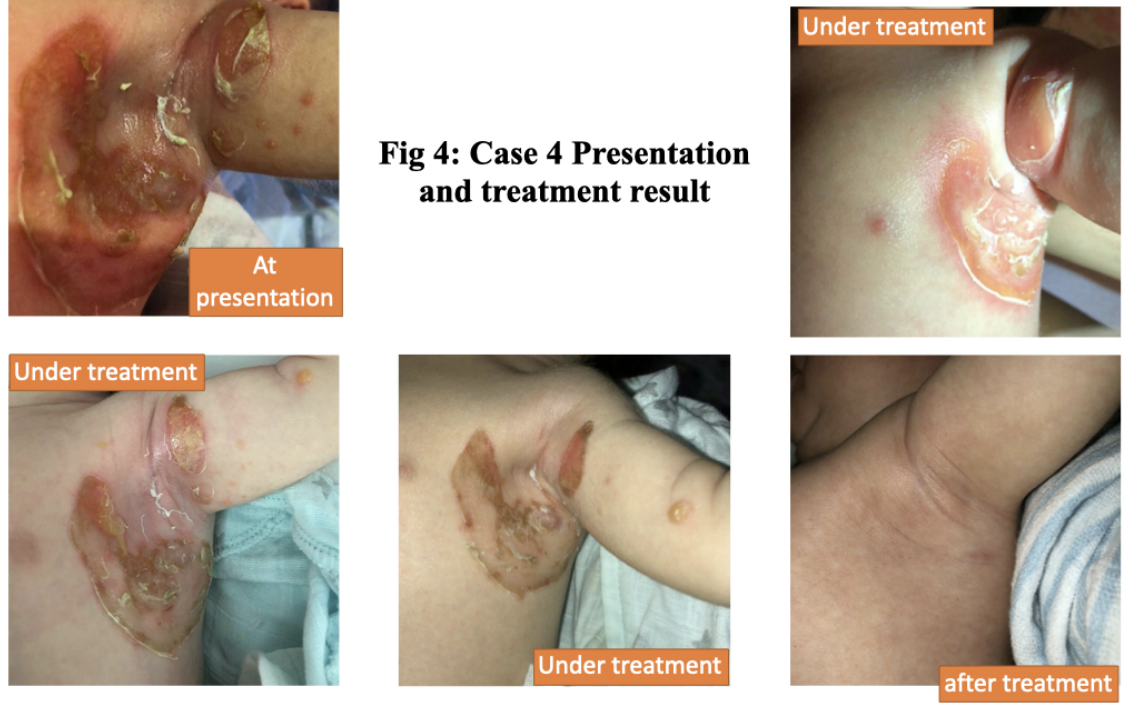